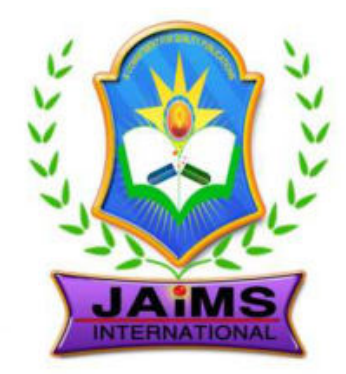

ISSN 2456-3110

Vol $4 \cdot$ Issue 6

Nov-Dec 2019

Journal of

Ayurveda and Integrated Medical Sciences

www.jaims.in

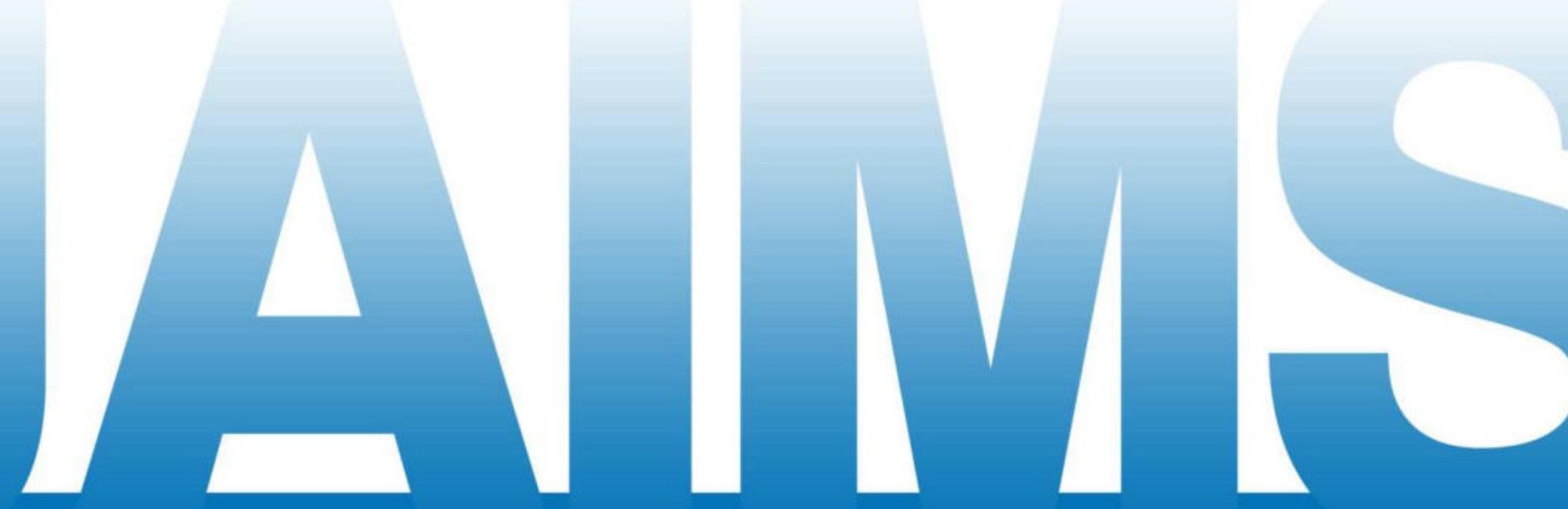

An International Journal for Researches in Ayurveda and Allied Sciences

Charaka

Publications 


\title{
Qualitative assessment of Swarnamakshika Bhasma (Copper Pyrite) using Nambhuri Phase Spot Test
}

\author{
Dr. Shrikanth A. S. ${ }^{1}$, Dr. P. G. Jadar. ${ }^{2}$
}

${ }^{1}$ Assistant Professor, Department of Rasa Shastra, Rajrajeshwari Ayurvedic Medical College and Hospital, Humnabad, Karnataka, ${ }^{2}$ Vice Principal, Department of Rasa Shastra and Bhaishajya Kalpana, BMK Ayurveda Medical College, Belgaum, Karnataka, INDIA.

\section{A B S T R A C T}

\begin{abstract}
Swarnamakshika is one among Maharasa (Great minerals), on reviewing the Ayurvedic classics, it is evident that therapeutic use of Swarnamakshika (Copper Pyrite) has been in practice since samhita kala (300B C- 600 B.C) period. Swarnamakshika (Copper Pyrite) used since time immemorial in treating various diseases like pandu (Anemia), kushta (Skin ailments), prameha (Diabetes) and it is best Rasayana (Immuno-modulatory) etc. Swarna Makshika (Copper pyrite) is the most abundant copper bearing mineral. Swarnamakshika (Copper Pyrite) was prepared according to the Ayurvedic classics and subjected to various bhasma parikshas (Powder test) as explained in Rasashastra (Indian Alchemy) text and also including the Namburi Phased Spot Test one of the qualitative tests described for various Ayurvedic preparations of Bhasma (Powder). NPST helps differentiate between purity of the sample, and thus identify, various bhasmas. It depends upon the pattern of the spot, which develops after a specific chemical reaction. Sample of Swarna Makshika Bhasma, (Swarnamakshika powder) which was tested with NPST the bhasmas (Ashes) prepared in our college, produced the most accurate results.
\end{abstract}

Key words: NPST, Swarnamakshika Bhasma, Copper pyrite, Namburi Phased Spot Test.

\section{INTRODUCTION}

In Indian chemistry the minerals of medicinal value are classified as Rasa, Maharasa, Uparasa, Sadharana rasa (Group of minerals), etc. Every member of these different groups, after purification and conversion into a colloidal form, may be used individually and independently or in a combined form. The members of the Maharasa group specially have their

\section{Address for correspondence:}

\section{Dr. Shrikanth A. S.}

Assistant Professor Department of Rasa Shastra, Rajrajeshwari Ayurvedic Medical College and Hospital, Humnabad, Karnataka, INDIA.

E-mail: drsherikar@gmail.com

Submission Date: 08/09/2019 Accepted Date: 15/11/2019

Quick Response Code

importance and their Bhasmas (Ashes) are used independently and their use of compounds also exists. Swarnamakshika (Copper Pyrite) is one among Maharasas (group of mineral), which has given very much importance in both Dhatuvada (stage of conversion of lower metals into higher metal) and Dehavada (stage of medicine preparation). It is a compound of copper, iron and sulphur along with so many toxic admixtures. Swarnamakshika (copper pyrite) in its bhasma form offers an improved state of Tamra bhasma (copper) pretreated by Gandhaka (sulphur) and Louha (iron) in its original form. It has been explained that if used without shodhana (purification) causes Akshivikaras (eye disease), Mandagni (undigetion), Kushta (Skin ailments) etc. disorders. Hence shodhana (purification) is necessary for it. Branch of Ayurveda However, in this competitive, commercialized world the quality of a bhasma (ashes) is always open to question to us. For bhasma (ashes) quality assessment, various bhasma parikshas (tests) have been described in our 
Rasashastra (Indian Alchemy) classics. The Namburi Phased Spot Test (NPST), a spot test based on a chemical reaction, is a new technique for assessing the quality of a prepared bhasma (ashes). When a drop of clear solution of a substance under examination (Bhasma or Sindhura) is put on specially prepared chemical reacting papers, a spot appears (Sindhura) which manifests a series of color and pattern changes. In chemistry, techniques involving spot tests or chromatography are widely used. The NPST involves observations of the spot and its color, at three successive phases spread over three different time intervals. It thus has the advantage of measuring sensitivity of reactions at different time intervals. In other words, it constitutes a method to study or detect, every second or even fraction of a second, continual chemical reactions taking place gradually between two chemical substances on static media. The technique was developedand standardized by Dr. Namburi Hanumantha Rao in 1970, it has been accepted by CCRAS, New Delhi. NPST and other classical tests were performed on samples of Swarnamakshika bhasma the first prepared classically using Gandhaka (sulphur) and Swarnamakshika (copper pyrite)triturated with Jambhira swarasa (citrus medica juice) 5 Varaha Puta are given. ${ }^{[1]}$ The bhasma prepared in our department shows the most accurate spots in Numbhuri phase spot test.

\section{Materials AND Methods}

A three-part methodology was used for this study

- Obtaining samples of Swarnamakshika bhasma first prepared classically as explained in Rasashastra (science of mercury) text.

- Subjecting sample to classical bhasma parikshas (ashes tests).

\section{- Subjecting sample to NPST}

\section{Swarnamakshika bhasma preparation classically}

The Raw Swarnamakshika was collected from (Hindustan Copper Ltd.) Khetri Copper Complex Khetri Nagar Rajasthan. It was having all grahya lakshanas (acceptable variety for the study) told in the classics. The Raw drug was confirmed by Quantitative analysis for Copper, Iron, and Sulphur using Atomic Absorption Spectrophotometer study

\section{Shodhana (purification) of Swarnamakshika (copper pyrite)}

Powder of Swarnamakshika (copper pyrite) was taken in an iron vessel. Erand Taila (Castor oil) was added to it and mixed properly. Then this iron vessel was kept on a gas stove for heating agni (fire) is in tivragni (intense fire). The mixture was then continuously stirred with the help of a small darvi (stirrer) throughout the procedure. Heating was stopped when the bottom of an iron vessel attained red color and all sulphur fumes stopped. Then the mixture was washed thoroughly with the hot water for two times and kept spread for drying on a clean cloth. ${ }^{[2]}$

Table 1: Showing the color change of Swarnamakshika churna during Bharjana (Frying).

\begin{tabular}{|l|l|}
\hline Procedure & Appearance \\
\hline Before Shodhana & Warm gray \\
\hline $\begin{array}{l}\text { After addition of Eranda } \\
\text { Taila (Castor oil) }\end{array}$ & Light gray \\
\hline $\begin{array}{l}\text { After 5min addition of } \\
\text { Eranda Taila (Castor oil) }\end{array}$ & Greenish gray \\
\hline After 15 min of heating & Blackish gray \\
\hline After 40 min of heating & Blackish gray red color \\
\hline
\end{tabular}

Marana of Swarnamakshika (Inceneration of copper pyrite)

Finely powdered shudda Swarnamakshika (purified copper pyrite) was taken in a Khalva yantra (mortar and pestle). Then equal quantity of Shudda gandhaka (purified sulphur) was added and triturated together till they become homogenous. To this mixture $100 \mathrm{ml}$ of Jambira rasa (citrus medica juice) was added triturated well till it becomes semisolid consistency. The paste were made into shape of chakrikas (round like) weighing $25 \mathrm{gm}$ and $8 \mathrm{~cm}$ uniformly and kept for drying. After drying they are kept in sharava (mud saucers )and sandi bandhana (sealing with rag and 
mud) is to be done and 5 varaha puta are given a fine dark brown color bhasma is obtain. In this study for complete bhasma lakshana appears it took total 8 no of putas. ${ }^{[3]}$

Subjecting sample to classical bhasma (ashes) parikshas

a) Rekhapurnata:

- A pinch of Swarnamakshika bhasma was rubbed in between thumb and index finger.

- It was observed whether bhasma enters the furrows of finger or not.Bhasma after $7^{\text {th }}$ puta passed this test.

b) Varitara:

- Clean water was taken in a glass and allowed to stand.A pinch of Swarnamakshika bhasmawas sprinkled on the surface of water.It was observed whether bhasma floats on the surface of the water or not. Bhasma after $7^{\text {th }}$ puta passed this test.

c) Unama:

- This is continuation of the above test where in rice grain is placed on the surface of bhasma. It is observed whether the floating still persists or not.Bhasma after $7^{\text {th }}$ passed this test.

d) Nishchandrata:

- A pinch of bhasma was taken and observed under bright sunlight.Bhasma after $7^{\text {th }}$ puta there were no shining particles in the bhasma.

e) Nirdhumatva:

- A pinch of bhasma was sprinkled on the ignited charcoal and observed for any fumes emerging out of it.There was no emerging of fumes when bhasma after $7^{\text {th }}$ puta was sprinkled.

Subjecting sample to NPST ${ }^{[4]}$

To verify the quality of the prepared Swarnamakshika Bhasma and to standardize the Swarnamakshika Bhasma the sample was subjected to NPST. Initially, 0.25 grams of each sample was taken in two separate test tubes. Each test tube was heated till the bottom appears red with the help of spirit lamp and they were allowed to self-cool. $0.5 \mathrm{ml}$ of $5 \% \mathrm{HCl}$ was taken in a graduated pipette and slowly dropped into the each test tube. Now again test tubes were heated for a while separately. The samples were allowed to stay for 24 hours.

Two hours before treating with a chemical reaction paper, the test tubes were shaken and then kept undisturbed. Then a drop of supernatant solution of each sample was dropped on the 2.55 Potassium Ferro cyanide paper with the help of dropper carefully. No sooner the drop came in contact with the $2.5 \%$ Potassium Ferro cyanide paper an instantaneous characteristic spot began to form and changes rapidly and continuously for some time.

Observation was made in following phases.

$I^{t}$ phase $\quad-0-5 \mathrm{~min}$.

II Phase $\quad-5 \min -20 \mathrm{~min}$

III Phase $\quad-20$ min-1 day.

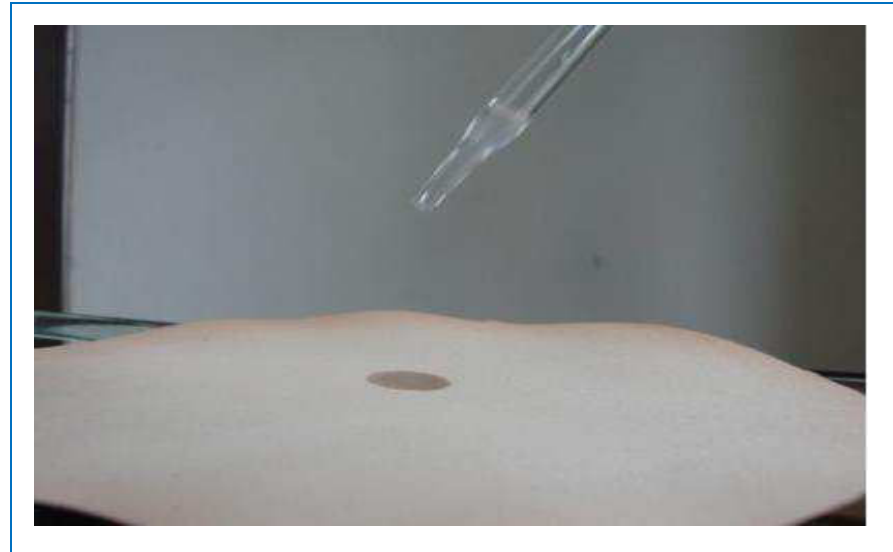

Figure 1: I Phase

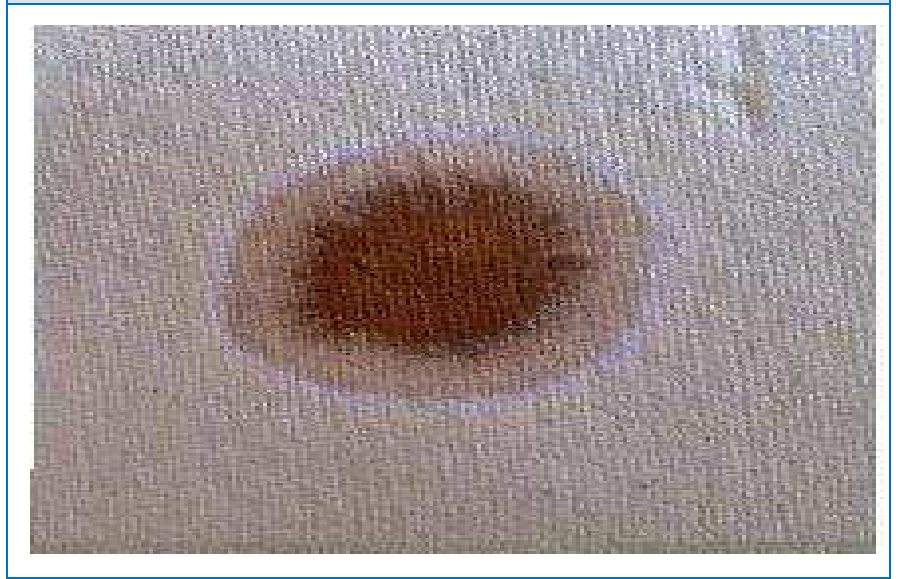




\section{Figure 2: II Phase}

\section{Figure 3: III Phase}

Table 2: Observation and result showing NPST results of Swarna Makshika Bhasma

\begin{tabular}{|l|l|l|l|l|}
\hline SN & Sample & I Phase & II Phase & III Phase \\
\hline 1. & SMB & $\begin{array}{l}\text { Dark brown } \\
\text { colored } \\
\text { central spot } \\
\text { with regular } \\
\text { margins Light } \\
\text { brown } \\
\text { periphery }\end{array}$ & $\begin{array}{l}\text { Dark brown } \\
\text { colored } \\
\text { central } \\
\text { spotWhite } \\
\text { ring ading of } \\
\text { periphery. }\end{array}$ & $\begin{array}{l}\text { Fadral } \\
\text { spot with } \\
\text { light } \\
\text { brown } \\
\text { margin. }\end{array}$ \\
\hline
\end{tabular}

\section{Discussion AND CONCLUSION}

The colors of the Swarnamakshika bhasma looks dark brown. It may be due to Marana (Incineration), and also on the number of puta given. As in classics mentioned 5 but it required 8 puta. The touch of the bhasma showed that very fine and smooth powder. A metallic taste was seen at the stage of $6^{\text {th }}$ puta which may indicate improper formation of the bhasma. Keeping this mind we given still 2 more putas than bhasma siddhi laxanas is seen clearly on the $8^{\text {th }}$ puta. Though samples passed the all the bhasma pariksha, like Varitara (Floats on water), Rekhapurnatva (farrows in the finger lines), unnama (loading with rice grain), nischandra (no shining particles), nirdhuma (no smoke) etc. showing that physico-chemically the bhasma was totally formed. If these tests show negative means then it would have indicatedthe presence of a metallic part in the bhasma and it is impossible to do the NPST test. In NPST the desired accurate spots were seen in Swarnamakshika Bhasma. Advantage of conducting NPST over other classical bhasma parikshas. The classical tests cannot differentiate between adulterated Bhasma and pure bhasmas chemically, but in NPST, as the test is basically chemical reaction, with specific resultsfor specific bhasmas, we can differentiate between adulterated and pure bhasmas clearly. This technique is very helpful for quality assessment of Bhasma as per the standards of Rasashastra. In other words, bhasmas can be identified by their name given in Rasashastra (Indian Alchemy) by virtue of their quality differences, but not chemically. It is such a simple test that it can be carried out with minimum set up and requirements. CCRAS has also accepted the monograph of NPST, and so the quality of Bhasma can be checked before being used therapeutically. Swarnamakshika bhasma which is prepared in our Rasashastra (Indian Alchemy) department gave results in accordance with the text.

\section{REFERENCES}

1. Somadeva Acharya, Rasendra Chudamani, Varanasi, Chaukhambha Orientalia, 1st Edition 1984, 165 PP

2. Vagbhatacharya, Rasa Ratna Samucchaya, edited by Dr.Ashok D.Satpute, $1^{\text {st }}$ edition,Delhi, Choukhamba Surbharati Prakashan, , 2003, $2^{\text {nd }}$ chapter verse $80,34 p p$

3. Somadeva Acharya, Rasendra Chudamani, Varanasi, Chaukhambha Orientalia, 1st Edition 1984, 165 PP

4. Dr. Rao Namburi H: Application of standardized Namburi Phased Spot Test. Project work submitted to CCRAS, New Delhi.

How to cite this article: Dr. Shrikanth A. S., Dr. P. G. Jadar. Qualitative assessment of Swarnamakshika Bhasma (Copper Pyrite) using Nambhuri Phase Spot Test. J Ayurveda Integr Med Sci 2019;6:71-74. http://dx.doi.org/10.21760/jaims.4.6.13

Source of Support: Nil, Conflict of Interest: None declared. 